\title{
Essential fruit, vegetables, and lists for health
}

\author{
Catherine McDermott deputy editor, The BMJ
}

We all know that eating fruit and vegetables is good for us, and a study in The BMJ this week adds to the now substantial evidence showing that people who eat more fruit and vegetables are more healthy and less likely to die prematurely. Wang and colleagues ask, "What is the association between consumption of fruit and vegetables and risk of all cause, cardiovascular, and cancer mortality?" (BMJ 2014;349:g4490, doi:10.1136/bmj. g4490).

Their systematic review and dose-response meta-analysis from 16 prospective cohort studies shows that higher consumption of fruit and vegetables was significantly associated with a lower risk of all cause mortality. They interestingly also observed "a threshold around five servings of fruits and vegetables a day after which the risk of all cause mortality did not reduce further."

The question of the health benefits of eating five, or more than five, daily portions of fruit and vegetables seems to be a topic that will be debated for some time to come (BMJ 2014;348:g2434, doi:10.1136/bmj.g2434). For now the UK government's advice remains that we should be consuming "at least" five servings of fruit and vegetables a day, which would seem to be in line with the most recent research.

Unfortunately, for a large part of the general public the benefits of healthy eating and lifestyle advice do not seem to be getting through. Authors of the latest clinical review (BMJ 2014;349:g4596, doi:10.1136/bmj.g4596) report that non-alcoholic fatty liver disease (NAFLD) is now more common worldwide than alcoholic liver disease, because of the rapid rise in the prevalence of obesity: prevalence of NAFLD is now $20 \%$ in the general population (and up to $70 \%$ in patients with type 2 diabetes).

The authors recommend that "patients with suspected or confirmed NAFLD should be given lifestyle advice on sustainable weight reduction as well as advice about reduction of alcohol intake" because obesity and alcohol may act synergistically to promote liver disease. With this in mind, are we as a profession going far enough to help provide practical advice for patients? Over and above endorsing public health advice about the benefits of five portions of fruit and vegetables a day, perhaps we need a similar evidence based checklist of "five foods and drinks NOT to consume each day," which would include refined sugar and sugary drinks.

Staying on the topic of lists, this week's Analysis by Barbui and Purgato (BMJ 2014;349:g4798, doi:10.1136/bmj.g4798) looks at the World Health Organization's list of essential medicines, which they say has had a "remarkable" effect, leading to "global acceptance of essential drugs as a powerful means to promote health equity worldwide." However, they say that a "more structured" and evidence based approach to accepting drugs for inclusion on the list would be a major step forward in terms of consistency and transparency to help ensure the list's continued success.

And finally, promoting health equity seems to have been a major goal of the pioneering HIV and AIDS researcher Joep Lange, whose obituary is published this week (BMJ 2014;349:g4827, doi:10.1136/bmj.g4827). Lange died, with 282 other passengers and 15 crew members, when Malaysian Airlines MH17 crashed in eastern Ukraine. In 1992, on his first visit to Africa, he wrote, "It became my mission to do something about the terrible global inequality in access to life-saving medicines."

Noting the contrast between the efficient infrastructure that allows the penetration of sugary drinks into all corners of the world and the difficulty in establishing a method for the safe delivery of drugs, he said, "If we can get cold Coca-Cola and beer to every remote corner of Africa, it should not be impossible to do the same with drugs." WHO's list of essential medicines has made a good start and should be supported. Wouldn't it be great if we could achieve further improvements in access to essential drugs_-but without the sugary drinks?

Cite this as: BMJ 2014;349:94906

๑ BMJ Publishing Group Ltd 2014 